\title{
Some Common Fixed Point Results for Rational Type Contraction Mappings in Complex Valued Metric Spaces
}

\author{
Sumit Chandok ${ }^{1}$ and Deepak Kumar ${ }^{2}$ \\ ${ }^{1}$ Department of Mathematics, Khalsa College of Engineering \& Technology (Punjab Technical University), Ranjit Avenue, \\ Amritsar 143001, India \\ ${ }^{2}$ Department of Mathematics, Lovely Professional University, Phagwara 144411, India
}

Correspondence should be addressed to Sumit Chandok; chansok.s@gmail.com

Received 21 March 2013; Accepted 8 May 2013

Academic Editor: Ram U. Verma

Copyright (C) 2013 S. Chandok and D. Kumar. This is an open access article distributed under the Creative Commons Attribution License, which permits unrestricted use, distribution, and reproduction in any medium, provided the original work is properly cited.

We prove some common fixed point theorems for two pairs of weakly compatible mappings satisfying a rational type contractive condition in the framework of complex valued metric spaces. The proved results generalize and extend some of the known results in the literature.

\section{Introduction and Preliminaries}

The famous Banach contraction principle states that if $(X, d)$ is a complete metric space and $T: X \rightarrow X$ is a contraction mapping (i.e., $d(T x, T y) \leq k d(x, y)$ for all $x, y \in X$, where $k$ is a nonnegative number such that $k<1$ ), then $T$ has a unique fixed point. This principle is one of the cornerstones in the development of nonlinear analysis. Fixed point theorems have applications not only in the different branches of mathematics, but also in economics, chemistry, biology, computer science, engineering, and others. Due to its importance, generalizations of Banach's contraction principle have been investigated heavily by several authors. Fixed point and common fixed point theorems for different types of nonlinear contractive mappings have been investigated extensively by various researchers (see [1-35] and references cited therein).

Recently, Azam et al. [1] introduced the complex valued metric space, which is more general than the well-known metric spaces. Many researchers have obtained fixed point, common fixed point, coupled fixed point, and coupled common fixed point results in partially ordered metric spaces, complex valued metric spaces, and other spaces. In this paper, we prove some common fixed point theorems for two pairs of weakly mappings satisfying a contractive condition of rational type in the framework of complex valued metric spaces. The proved results generalize and extend some of the results in the literature.

To begin with, we recall some basic definitions, notations, and results.

The following definitions of Azam et al. [1] are needed in the sequel.

Let $\mathbb{C}$ be the set of complex numbers, and let $z_{1}, z_{2} \in \mathbb{C}$. Define a partial order $\leq$ on $\mathbb{C}$ as follows:

$$
\begin{gathered}
z_{1} \leq z_{2} \quad \text { iff } \operatorname{Re}\left(z_{1}\right) \leq \operatorname{Re}\left(z_{2}\right), \\
\operatorname{Im}\left(z_{1}\right) \leq \operatorname{Im}\left(z_{2}\right) .
\end{gathered}
$$

It follows that $z_{1} \leq z_{2}$ if one of the following conditions is satisfied:

(1) $\operatorname{Re}\left(z_{1}\right)=\operatorname{Re}\left(z_{2}\right)$, and $\operatorname{Im}\left(z_{1}\right)<\operatorname{Im}\left(z_{2}\right)$;

(2) $\operatorname{Re}\left(z_{1}\right)<\operatorname{Re}\left(z_{2}\right)$, and $\operatorname{Im}\left(z_{1}\right)=\operatorname{Im}\left(z_{2}\right)$;

(3) $\operatorname{Re}\left(z_{1}\right)<\operatorname{Re}\left(z_{2}\right)$, and $\operatorname{Im}\left(z_{1}\right)<\operatorname{Im}\left(z_{2}\right)$;

(4) $\operatorname{Re}\left(z_{1}\right)=\operatorname{Re}\left(z_{2}\right)$, and $\operatorname{Im}\left(z_{1}\right)=\operatorname{Im}\left(z_{2}\right)$.

In particular, we will write $z_{1} \lesseqgtr z_{2}$ if $z_{1} \neq z_{2}$ and one of (1), (2), and (3) is satisfied, and we will write $z_{1}<z_{2}$ if only (3) is satisfied. 
Note. We obtained that the following statements hold:

(i) $a, b \in \mathbb{R}$ and $a \leq b \Rightarrow a z \leq b z$, for all $z \in \mathbb{C}$;

(ii) $0 \leq z_{1} \nless z_{2} \Rightarrow\left|z_{1}\right|<\left|z_{2}\right|$;

(iii) $z_{1} \leq z_{2}$ and $z_{2}<z_{3}$ imply $z_{1}<z_{3}$.

Definition 1. Let $X$ be a nonempty set. Suppose that the mapping $d: X \times X \rightarrow \mathbb{C}$ satisfies the following conditions:

(i) $0 \leq d(x, y)$ for all $x, y \in X$ and $d(x, y)=0$ if and only if $x=y$;

(ii) $d(x, y)=d(y, x)$ for all $x, y \in X$;

(iii) $d(x, y) \leq d(x, z)+d(z, y)$ for all $x, y, z \in X$.

Then, $d$ is called a complex valued metric on $X$, and $(X, d)$ is called a complex valued metric space.

Example 2. Let $X=\mathbb{C}$. Define a mapping $d: X \times X \rightarrow \mathbb{C}$ by

$$
d\left(z_{1}, z_{2}\right)=e^{i k}\left|z_{1}-z_{2}\right|
$$

where $k \in[0, \pi / 2]$. Then, $(X, d)$ is a complex valued metric space.

A point $x \in X$ is called an interior point of a set $A \subseteq X$ whenever there exists $0<r \in \mathbb{C}$ such that $B(x, r)=\{y \in$ $X: d(x, y)<r\} \subseteq A$. A subset $A$ in $X$ is called open, whenever each point of $A$ is an interior point of $A$. The family $F=\{B(x, r): x \in X, 0<r\}$ is a subbasis for a Hausdorff topology on $X$.

A point $x \in X$ is called a limit point of $A$, whenever for every $0<r \in \mathbb{C}, B(x, r) \cap(A \backslash X) \neq \emptyset$. A subset $B \subseteq X$ is called closed, whenever each limit point of $B$ belongs to $B$.

Let $\left\{x_{n}\right\}$ be a sequence in $X$ and $x \in X$. If for every $c \in \mathbb{C}$, with $0<c$, there is $n_{0} \in \mathbb{N}$ such that for all $n>n_{0}, d\left(x_{n}, x\right)<$ $c$, then $x$ is called the limit of $\left\{x_{n}\right\}$, and we write $\lim _{n \rightarrow \infty} x_{n}=$ $x$.

If for every $c \in \mathbb{C}$, with $0<c$, there is an $n_{0} \in \mathbb{N}$ such that for all $n>n_{0}, d\left(x_{n}, x_{n+m}\right)<c$, then $\left\{x_{n}\right\}$ is called a Cauchy sequence in $(X, d)$. If every Cauchy sequence is convergent in $(X, d)$, then $(X, d)$ is called a complete complex valued metric space.

Lemma 3 (see [1]). Let $(X, d)$ be a complex valued metric space and $\left\{x_{n}\right\}$ a sequence in $X$. Then, $\left\{x_{n}\right\}$ converges to $x$ if and only if $\left|d\left(x_{n}, x\right)\right| \rightarrow 0$ as $n \rightarrow \infty$.

Lemma 4 (see [1]). Let $(X, d)$ be a complex valued metric space and $\left\{x_{n}\right\}$ a sequence in $X$. Then, $\left\{x_{n}\right\}$ is a Cauchy sequence if and only if $\left|d\left(x_{n}, x_{n+m}\right)\right| \rightarrow 0$ as $n \rightarrow \infty$.

Let $M$ be a nonempty subset of a metric space $(X, d)$. Let $S$ and $T$ be mappings from a metric space $(X, d)$ into itself. A point $x \in M$ is a common fixed (resp., coincidence) point of $S$ and $T$ if $x=S x=T x$ (resp., $S x=T x$ ). The set of fixed points (resp., coincidence points) of $S$ and $T$ is denoted by $F(S, T)$ (resp., $C(S, T)$ ).

In 1986, Jungck [22] introduced the more generalized commuting mappings in metric spaces, called compatible mappings, which also are more general than the concept of weakly commuting mappings (i.e., the mappings $S, T$ : $X \rightarrow X$ are said to be weakly commuting if $d(S T x, T S x) \leq$ $d(S x, T x)$ for all $x \in X)$ introduced by Sessa [28].

Definition 5. Let $S$ and $T$ be mappings from a metric space $(X, d)$ into itself. The mappings $S$ and $T$ are said to be compatible if

$$
\lim _{n \rightarrow \infty} d\left(S T x_{n}, T S x_{n}\right)=0
$$

whenever $\left\{x_{n}\right\}$ is a sequence in $X$ such that $\lim _{n \rightarrow \infty} S x_{n}=$ $\lim _{n \rightarrow \infty} T x_{n}=z$ for some $z \in X$.

In general, commuting mappings are weakly commuting, and weakly commuting mappings are compatible, but the converses are not necessarily true, and some examples can be found in [22-24].

Definition 6. The mappings $S$ and $T$ are said to be weakly compatible if they commute at coincidence points of $S$ and $T$.

Definition 7. Let T,S :X $\rightarrow X$ be two self-mappings of a complex valued metric space $(X, d)$. The pair $(T, S)$ is said to satisfy (E.A.) property (see [35]) if there exists a sequence $\left\{x_{n}\right\}$ in $X$ such that $\lim _{n \rightarrow \infty} T x_{n}=\lim _{n \rightarrow \infty} S x_{n}=t$, for some $t \epsilon$ $X$.

Pathak et al. [27] showed that weakly compatibility and (E.A.) property are independent of each other.

Definition 8. The self mappings $T$ and $S$ from $X$ to $X$ are said to satisfy the common limit in the range of $S$ property $\left(C L R_{S}\right.$ property) (see [31]) if $\lim _{n \rightarrow \infty} T x_{n}=\lim _{n \rightarrow \infty} S x_{n}=$ $S x$, for some $x \in X$.

Some recent papers related to $(C L R)$ property and the complex valued metric spaces can be found in $[1,3,27,31-$ 35] and references cited therein.

\section{Main Results}

2.1. Common Fixed Point Theorem Using (E.A.) Property. In this section, we prove some common fixed point theorems using (E.A.) property in the complex valued metric spaces.

Theorem 9. Let $(X, d)$ be a complex valued metric space and $A, B, S, T: X \rightarrow X$ four self-mappings satisfying the following conditions:

(i) $A(X) \subseteq T(X), B(X) \subseteq S(X)$;

(ii) for all $x, y \in X$ and $0<a<1$,

$$
\begin{aligned}
& d(A x, B y) \\
& \quad \leq a \frac{d(S x, A x) d(S x, B y)+d(T y, B y) d(T y, A x)}{1+d(S x, B y)+d(T y, A x)}
\end{aligned}
$$

(iii) the pairs $(A, S)$ and $(B, T)$ are weakly compatible;

(iv) one of the pairs $(A, S)$ or $(B, T)$ satisfies (E.A.)-property. 
If the range of one of the mappings $S(X)$ or $T(X)$ is a closed subspace of $X$, then the mappings $A, B, S$, and $T$ have a unique common fixed point in $X$.

Proof. First, we suppose that the pair $(B, T)$ satisfies (E.A.) property. Then, by Definition 7 there exists a sequence $\left\{x_{n}\right\}$ in $X$ such that $\lim _{n \rightarrow \infty} B x_{n}=\lim _{n \rightarrow \infty} T x_{n}=t$ for some $t \in X$.

Further, since $B(X) \subseteq S(X)$, there exists a sequence $\left\{y_{n}\right\}$ in $X$ such that $B x_{n}=S y_{n}$. Hence, $\lim _{n \rightarrow \infty} S y_{n}=t$. We claim that $\lim _{n \rightarrow \infty} A y_{n}=t$. Let $\lim _{n \rightarrow \infty} A y_{n}=t_{1} \neq t$, then putting $x=y_{n}, y=x_{n}$ in condition (ii), we have

$$
\begin{aligned}
& d\left(A y_{n}, B x_{n}\right) \\
& \quad \leq a \frac{d\left(S y_{n}, A y_{n}\right) d\left(S y_{n}, B x_{n}\right)+d\left(T x_{n}, B x_{n}\right) d\left(T x_{n}, A y_{n}\right)}{1+d\left(S y_{n}, B x_{n}\right)+d\left(T x_{n}, A y_{n}\right)}
\end{aligned}
$$

Letting $n \rightarrow \infty$, we have

$$
d\left(t_{1}, t\right) \leq a \frac{d\left(t, t_{1}\right) d(t, t)+d(t, t) d\left(t, t_{1}\right)}{1+d(t, t)+d\left(t, t_{1}\right)} .
$$

Then, $\left|d\left(t_{1}, t\right)\right| \leq 0$; hence, $t_{1}=t$ and that is, $\lim _{n \rightarrow \infty} A y_{n}=$ $\lim _{n \rightarrow \infty} B x_{n}=t$.

Now suppose that $S(X)$ is a closed subspace of $X$, then $t=S u$ for some $u \in X$. Subsequently, we have

$$
\begin{aligned}
\lim _{n \rightarrow \infty} A y_{n} & =\lim _{n \rightarrow \infty} B x_{n}=\lim _{n \rightarrow \infty} T x_{n} \\
& =\lim _{n \rightarrow \infty} S y_{n}=t=S u .
\end{aligned}
$$

We claim that $A u=S u$. Put $x=u$ and $y=x_{n}$ in contractive condition (ii), and we have

$$
\begin{aligned}
& d\left(A u, B x_{n}\right) \\
& \quad \leq a \frac{d(S u, A u) d\left(S u, B x_{n}\right)+d\left(T x_{n}, B x_{n}\right) d\left(T x_{n}, A u\right)}{1+d\left(S u, B x_{n}\right)+d\left(T x_{n}, A u\right)} .
\end{aligned}
$$

Letting $n \rightarrow \infty$ and using (7), we have

$$
d(A u, t) \leq a \frac{d(t, A u) d(t, t)+d(t, t) d(t, A u)}{1+d(t, t)+d(t, A u)} .
$$

Then, $|d(A u, t)| \leq 0$, which is contradiction. Hence, $u$ is a coincidence point of $(A, S)$.

Now the weak compatibility of pair $(A, S)$ implies that $A S u=S A u$ or $A t=S t$.

On the other hand, since $A(X) \subseteq T(X)$, there exists $v$ in $X$ such that $A u=T v$. Thus, $A u=S u=T v=t$. Now, we show that $v$ is a coincidence point of $(B, T)$; that is, $B v=T v=t$. Put $x=u, y=v$ in contractive condition (ii), and we have

$$
\begin{aligned}
& d(A u, B v) \\
& \quad \leq a \frac{d(S u, A u) d(S u, B v)+d(T v, B v) d(T v, A u)}{1+d(S u, B v)+d(T v, A u)}
\end{aligned}
$$

or

$$
d(t, B v) \leq a \frac{d(t, t) d(t, B v)+d(t, B v) d(t, t)}{1+d(t, B v)+d(t, t)}
$$

whence $|d(t, B v)| \leq 0$, which is a contradiction. Thus, $B v=t$. Hence, $B v=T v=t$, and $v$ is the coincidence point of $B$ and $T$.

Further, the weak compatibility of pair $(B, T)$ implies that $B T v=T B v$, or $B t=T t$. Therefore, $t$ is a common coincidence point of $A, B, S$, and $T$.

Now, we show that $t$ is a common fixed point. Put $x=u$ and $y=t$ in contractive condition (ii), and we have

$$
\begin{aligned}
d(t, B t) & =d(A u, B t) \\
& \leq a \frac{d(S u, A u) d(S u, B t)+d(T t, B t) d(T t, A u)}{1+d(S u, B t)+d(T t, A u)},
\end{aligned}
$$

or $|d(t, B t)| \leq 0$, which is a contradiction. Thus, $B t=t$. Hence, $A t=B t=S t=T t=t$.

Similar argument arises if we assume that $T(X)$ is closed subspace of $X$. Similarly, the (E.A.)-property of the pair $(A, S)$ will give a similar result.

For uniqueness of the common fixed point, let us assume that $w$ is another common fixed point of $A, B, S$, and $T$. Then, put $x=w, y=t$ in contractive condition (ii), and we have

$$
\begin{aligned}
d(w, t) & =d(A w, B t) \\
& \leq a \frac{d(S w, A w) d(S w, B t)+d(T t, B t) d(T t, A w)}{1+d(S w, B t)+d(T t, A w)}
\end{aligned}
$$

or $|d(w, t)| \leq 0$, which is a contradiction. Thus, $w=t$. Hence, $A t=B t=S t=T t=t$, and $t$ is the unique common fixed point of $A, B, S$, and $T$.

Remark 10. (a) Continuity of mappings $A, B, S$, and $T$ is relaxed in Theorem 9.

(b) Completeness of space $X$ is relaxed in Theorem 9.

If $A=B$ and $S=T$ in Theorem 9, we have the following result.

Corollary 11. Let $(X, d)$ be a complex valued metric space and $A, T: X \rightarrow X$ self-mappings satisfying the following conditions:

(i) $A(X) \subseteq T(X)$;

(ii) for all $x, y \in X$ and $0<a<1$,

$$
\begin{aligned}
& d(A x, A y) \\
& \quad \leq a \frac{d(T x, A x) d(T x, A y)+d(T y, A y) d(T y, A x)}{1+d(T x, A y)+d(T y, A x)}
\end{aligned}
$$

(iii) the pair $(A, T)$ is weakly compatible;

(iv) the pair $(A, T)$ satisfies (E.A.)-property.

If the range of the mapping $T(X)$ is a closed subspace of $X$, then $A$ and $T$ have a unique common fixed point in $X$. 
Theorem 12. Let $(X, d)$ be a complex valued metric space and $A, B, S, T: X \rightarrow X$ four self-mappings satisfying the following conditions:

(i) $A(X) \subseteq T(X), B(X) \subseteq S(X)$;

(ii) for all $x, y \in X$ and $0<a<1$,

$$
d(A x, B y) \leq\left\{\begin{array}{lr}
a \frac{d(S x, A x) d(S x, B y)+d(T y, B y) d(T y, A x)}{d(S x, B y)+d(T y, A x)}, & \text { if } D \neq 0 \\
0, & \text { if } D=0,
\end{array}\right.
$$

where $D=d(S x, B y)+d(T y, A x)$;

(iii) the pairs $(A, S)$ and $(B, T)$ are weakly compatible;

(iv) one of the pairs $(A, S)$ or $(B, T)$ satisfies (E.A.)-property. If the range of one of the mappings $S(X)$ or $T(X)$ is a closed subspace of $X$, then the mappings $A, B, S$, and $T$ have a unique common fixed point in $X$.

Proof. Using the same arguments as in Theorem 9, we have the following result.

2.2. Fixed Point Theorem Using (CLR)-Property. In this section, we prove some common fixed point theorems using (CLR) property in the complex valued metric spaces.

Theorem 13. Let $(X, d)$ be a complex valued metric space and $A, B, S$, and $T: X \rightarrow X$ four self-mappings satisfying the following conditions:

(i) $A(X) \subseteq T(X), B(X) \subseteq S(X)$;

(ii) for all $x, y \in X$ and $0<a<1$,

$$
\begin{aligned}
& d(A x, B y) \\
& \quad \leq a \frac{d(S x, A x) d(S x, B y)+d(T y, B y) d(T y, A x)}{1+d(S x, B y)+d(T y, A x)}
\end{aligned}
$$

(iii) the pairs $(A, S)$ and $(B, T)$ are weakly compatible.

If the pair $(A, S)$ satisfies $\left(C L R_{A}\right)$ property or $(B, T)$ satisfies $\left(C L R_{B}\right)$ property, then $A, B, S$ and $T$ have a unique common fixed point in $X$.

Proof. First, we suppose that the pair $(B, T)$ satisfies $\left(\mathrm{CLR}_{B}\right)$ property. Then, by Definition 8 , there exists a sequence $\left\{x_{n}\right\}$ in $X$ such that

$$
\lim _{n \rightarrow \infty} B x_{n}=\lim _{n \rightarrow \infty} T x_{n}=B x,
$$

for some $x \in X$.

Further, since $B(X) \subseteq S(X)$, we have $B x=S u$, for some $u \in X$. We claim that $A u=S u=t$ (say). Put $x=u$ and $y=x_{n}$ in contractive condition (ii), and we have

$$
\begin{aligned}
& d\left(A u, B x_{n}\right) \\
& \quad \leq a \frac{d(S u, A u) d\left(S u, B x_{n}\right)+d\left(T x_{n}, B x_{n}\right) d\left(T x_{n}, A u\right)}{1+d\left(S u, B x_{n}\right)+d\left(T x_{n}, A u\right)}
\end{aligned}
$$

letting $n \rightarrow \infty$ and using (17), we have

$d(A u, B x)$

$$
\leq a \frac{d(S u, A u) d(S u, B x)+d(B x, B x) d(B x, A u)}{1+d(S u, B x)+d(B x, A u)} .
$$

Then, $|d(A u, B x)| \leq 0$, which is contradiction. Thus, $A u=$ $S u$. Hence, $A u=S u=B x=t$.

Now, the weak compatibility of pair $(A, S)$ implies that, $A S u=S A u$ or $A t=S t$.

Further, since $A(X) \subseteq T(X)$, there exists $v$ in $X$ such that $A u=T v$. Thus, $A u=S u=T v=t$.

Now, we show that $v$ is a coincidence point of $(B, T)$ that is, $B v=T v=t$. Put $x=u, y=v$ in contractive condition (ii), and we have

$d(A u, B v)$

$$
\leq a \frac{d(S u, A u) d(S u, B v)+d(T v, B v) d(T v, A u)}{1+d(S u, B v)+d(T v, A u)},
$$

or

$$
d(t, B v) \leq a \frac{d(t, t) d(t, B v)+d(t, B v) d(t, t)}{1+d(t, B v)+d(t, t)}
$$

whence $|d(t, B v)| \leq 0$, which is a contradiction. Thus, $B v=t$. Hence, $B v=T v=t$, and $v$ is coincidence point of $B$ and $T$.

Further, the weak compatibility of pair $(B, T)$ implies that $B T v=T B v$, or $B t=T t$. Therefore, $t$ is a common coincidence point of $A, B, S$, and $T$.

Now, we show that $t$ is a common fixed point. Put $x=u$ and $y=t$ in contractive condition (ii), and we have

$$
\begin{aligned}
d(t, B t) & =d(A u, B t) \\
& \leq a \frac{d(S u, A u) d(S u, B t)+d(T t, B t) d(T t, A u)}{1+d(S u, B t)+d(T t, A u)}
\end{aligned}
$$

or $|d(t, B t)| \leq 0$, which is a contradiction. Thus, $B t=t$. Hence, $A t=B t=S t=T t=t$. The uniqueness of the common fixed point follows easily.

In a similar way, the argument that the pair $(A, S)$ satisfies property $\left(\mathrm{CLR}_{A}\right)$ will also give the unique common fixed point of $A, B, S$ and $T$. Hence the result follows.

Following the similar steps as in Theorem 13, we have the following result.

Theorem 14. Let $(X, d)$ be a complex valued metric space and $A, B, S$, and $T: X \rightarrow X$ four self-mappings satisfying the following conditions:

(i) $A(X) \subseteq T(X), B(X) \subseteq S(X)$;

(ii) for all $x, y \in X$ and $0<a<1$,

$d(A x, B y) \leq\left\{\begin{array}{lr}a \frac{d(S x, A x) d(S x, B y)+d(T y, B y) d(T y, A x)}{d(S x, B y)+d(T y, A x)} & \text { if } D \neq 0 \\ 0, & \text { if } D=0,\end{array}\right.$

where $D=d(S x, B y)+d(T y, A x)$;

(iii) the pairs $(A, S)$ and $(B, T)$ are weakly compatible. 
If the pair $(A, S)$ satisfy $\left(C L R_{A}\right)$ property or $(B, T)$ satisfies $\left(C L R_{B}\right)$ property, then $A, B, S$, and $T$ have a unique common fixed point in $X$.

Remark 15. In this paper, we used the (E.A.) property and CLR property to claim the existence of common fixed point of some rational type contraction mappings. (E.A.) property requires the condition of closedness of subspace. However, CLR property never requires any condition on closedness of subspace, continuity of one or more mappings and containment of ranges of involved mappings. So, CLR property is an interesting auxiliary tool to claim the existence of a common fixed point.

\section{Acknowledgment}

The authors are thankful to the learned referees for the very careful reading and valuable suggestions.

\section{References}

[1] A. Azam, B. Fisher, and M. Khan, "Common fixed point theorems in complex valued metric spaces," Numerical Functional Analysis and Optimization, vol. 32, no. 3, pp. 243-253, 2011.

[2] G. V. R. Babu and P. Subhashini, "Coupled common fixed point theorems of Ciric type $g$-weak contractions with CLRgproperty," Journal of Nonlinear Analysis and Optimization: Theory and Applications. In press.

[3] S. Bhatt, S. Chaukiyal, and R. C. Dimri, "A common fixed point theorem for weakly compatible maps in complex valued metric spaces," International Journal of Mathematical Sciences \& Applications, vol. 1, no. 3, pp. 1385-1389, 2011.

[4] S. Chandok, "Some common fixed point theorems for generalized nonlinear contractive mappings," Computers \& Mathematics with Applications, vol. 62, no. 10, pp. 3692-3699, 2011.

[5] S. Chandok, "Common fixed points, invariant approximation and generalized weak contractions," International Journal of Mathematics and Mathematical Sciences, vol. 2012, Article ID 102980, 11 pages, 2012.

[6] S. Chandok, "Some common fixed point theorems for Ciric type contraction mapping," Tamkang Journal of Mathematics, vol. 43, no. 2, pp. 187-202, 2012.

[7] S. Chandok, "Common fixed points for generalized nonlinear contractive mappings in metric spaces," Matematichki Vesnik, vol. 65, no. 1, pp. 29-34, 2013.

[8] S. Chandok, "Some common fixed point theorems for a pair of different compatible type mappings," Annales Ordea UniversityMatematică Fascicola, vol. 20, no. 2, 2013.

[9] S. Chandok, "Some common fixed point results for generalized weak contractive mappings in partially ordered metric spaces," Journal of Nonlinear Analysis and Optimization: Theory and Applications, vol. 4, no. 1, pp. 45-52, 2013.

[10] S. Chandok, M. S. Khan, and K. P. R. Rao, "Some coupled common fixed point theorems for a pair of mappings satisfying a contractive condition of rational type without monotonicity," International Journal of Mathematical Analysis, vol. 7, no. 9-12, pp. 433-440, 2013.

[11] S. Chandok and J. K. Kim, "Fixed point theorem in ordered metric spaces for generalized contractions mappings satisfying rational type expressions," Journal of Nonlinear Functional Analysis and Application, vol. 17, no. 3, pp. 301-306, 2012.
[12] S. Chandok, J. Liang, and D. O’Regan, “Common fixed points and invariant approximations for noncommuting contraction mappings in strongly convex metric spaces," Journal of Nonlinear and Convex Analysis, vol. 14, 2013.

[13] S. Chandok, Z. Mustafa, and M. Postolache, "Coupled common fixed point theorems for mixed $g$-monotone mappings in partially ordered G-metric spaces," UPB Scientific Bulletin A. In press.

[14] S. Chandok, T. D. Narang, and M. A. Taoudi, "Some common fixed point results in partially ordered metric spaces for generalized rational type contraction mappings," Vietnam Journal of Mathematics.

[15] S. Chauhan, W. Sintunavarat, and P. Kumam, "Common fixed point theorems for weakly compatible mappings in fuzzy metric spaces using (JCLR)-property," Applied Mathematics, vol. 3, no. 9, pp. 976-982, 2012.

[16] S. Chauhan, "Fixed points of weakly compatible mappings in fuzzy metric spaces satisfying common limit in the range property," Indian Journal of Mathematics, vol. 54, no. 3, pp. 375-397, 2012.

[17] S. Chauhan, S. Bhatnagar, and S. Radenovic, "Common fixed point theorems for weakly compatible mappings infuzzy metric spaces," Le Matematiche. In press.

[18] S. D. Diwan and R. Gupta, "A common fixed point theorem for Gregus type mappings," Thai Journal of Mathematics. In press.

[19] M. Imdad, B. D. Pant, and S. Chauhan, "Fixed point theorems in Menger spaces using the CLR $R_{S T}$ property and applications," Journal of Nonlinear Analysis and Optimization, vol. 3, no. 2, pp. 225-237, 2012.

[20] M. Jain, K. Tas, S. Kumar, and N. Gupta, "Coupled fixed point theorems for a pair of weakly compatible maps along with CLRg-property in fuzzy metric spaces," Journal of Applied Mathematics, vol. 2012, Article ID 961210, 13 pages, 2012.

[21] M. Jain and S. Kumar, "A common fixed point theorem in fuzzy metric space using the property (CLRg)," Thai Journal of Mathematics. In press.

[22] G. Jungck, "Compatible mappings and common fixed points," International Journal of Mathematics and Mathematical Sciences, vol. 9, no. 4, pp. 771-779, 1986.

[23] G. Jungck, "Compatible mappings and common fixed points. II," International Journal of Mathematics and Mathematical Sciences, vol. 11, no. 2, pp. 285-288, 1988.

[24] G. Jungck, "Common fixed points for commuting and compatible maps on compacta," Proceedings of the American Mathematical Society, vol. 103, no. 3, pp. 977-983, 1988.

[25] G. Jungck and B. E. Rhoades, "Fixed point theorems for occasionally weakly compatible mappings," Fixed Point Theory, vol. 7, no. 2, pp. 287-296, 2006.

[26] M. Kumar, P. Kumar, and S. Kumar, "Some common fixed point theorems using (CLRg)-property in cone metric spaces," Advances Fixed Point Theory, vol. 2, no. 3, pp. 340-356, 2012.

[27] H. K. Pathak, R. Rodríguez-López, and R. K. Verma, "A common fixed point theorem of integral type using implicit relation," Nonlinear Functional Analysis and Applications, vol. 15, no. 1, pp. 1-12, 2010.

[28] S. Sessa, "On a weak commutativity condition of mappings in fixed point considerations," Institut Mathématique. Publications, vol. 32, no. 46, pp. 149-153, 1982.

[29] W. Sintunavarat and P. Kumam, "Weak condition for generalized multi-valued $(f, \alpha, \beta)$-weak contraction mappings," Applied Mathematics Letters, vol. 24, no. 4, pp. 460-465, 2011. 
[30] W. Sintunavarat, Y. J. Cho, and P. Kumam, "Common fixed point theorems for $c$-distance in ordered cone metric spaces," Computers \& Mathematics with Applications, vol. 62, no. 4, pp. 19691978, 2011.

[31] W. Sintunavarat and P. Kumam, "Common fixed point theorems for a pair of weakly compatible mappings in fuzzy metric spaces," Journal of Applied Mathematics, vol. 2011, Article ID 637958, 14 pages, 2011.

[32] W. Sintunavarat and P. Kumam, "Generalized common fixed point theorems in complex valued metric spaces and applications," Journal of Inequalities and Applications, vol. 2012, article 84, 2012.

[33] W. Sintunavarat and P. Kumam, "Common fixed points for $R$-weakly commuting in fuzzy metric spaces," Annali dell'Universitá di Ferrara, vol. 58, no. 2, pp. 389-406, 2012.

[34] W. Sintunavarat, Y. J. Cho, and P. Kumam, "Urysohn integral equations approach by common fixed points in complex valued metric spaces," Advances in Difference Equations, vol. 2013, article 49, 2013.

[35] R. K. Verma and H. K. Pathak, "Common fixed point theorems using property (E.A) in complex-vauled metric spaces," Thai Journal of Mathematics. In press. 


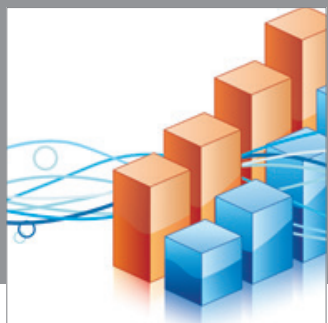

Advances in

Operations Research

mansans

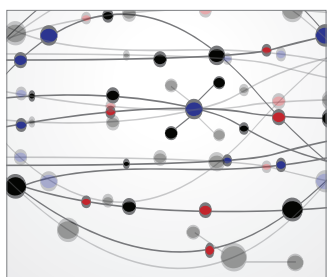

The Scientific World Journal
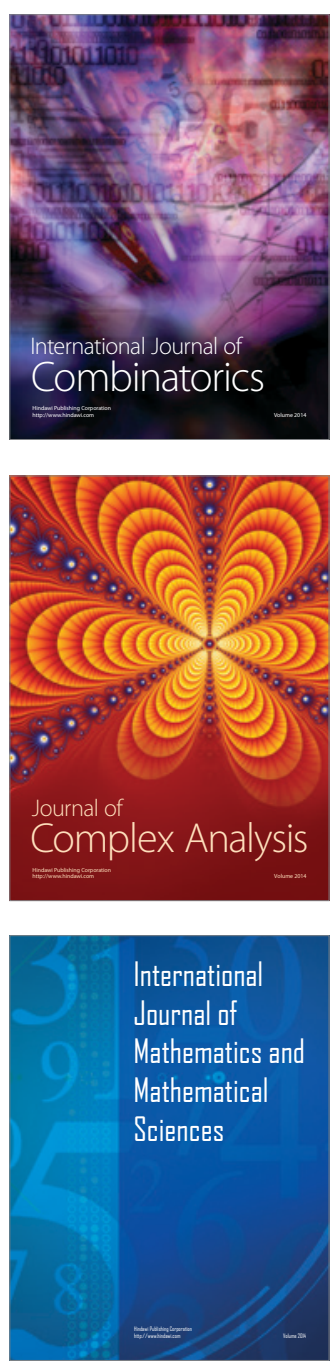
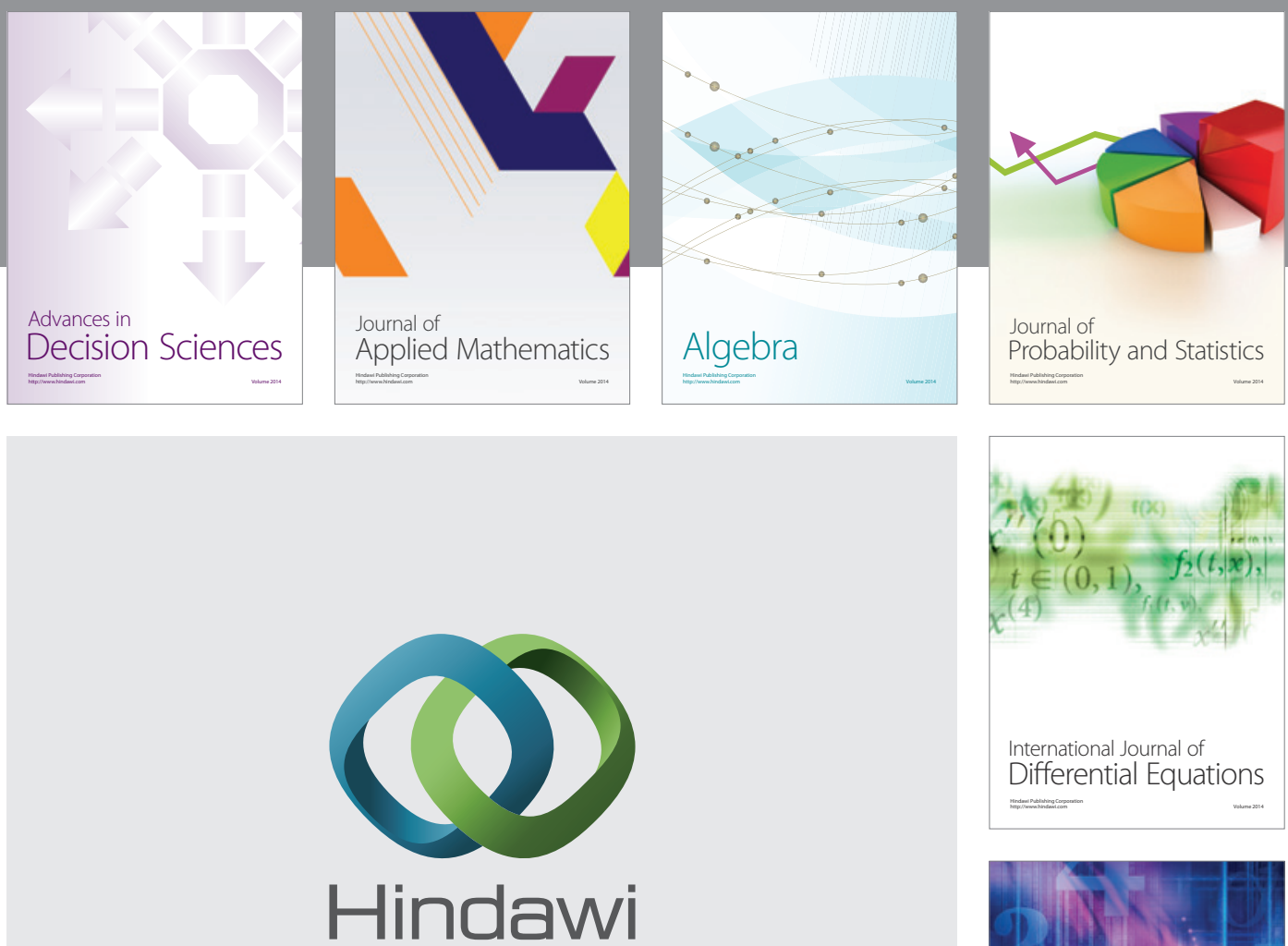

Submit your manuscripts at http://www.hindawi.com
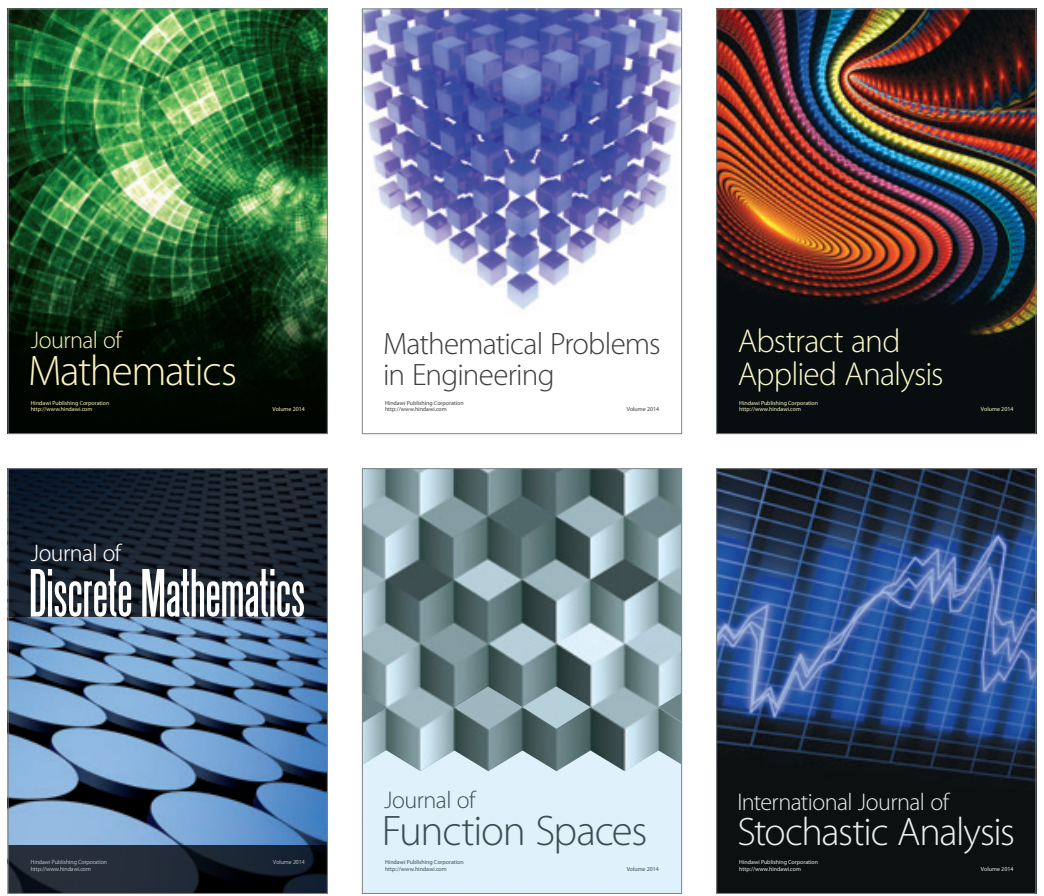

Journal of

Function Spaces

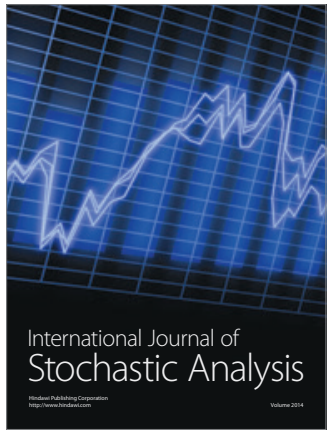

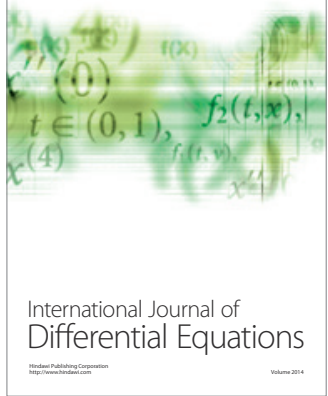
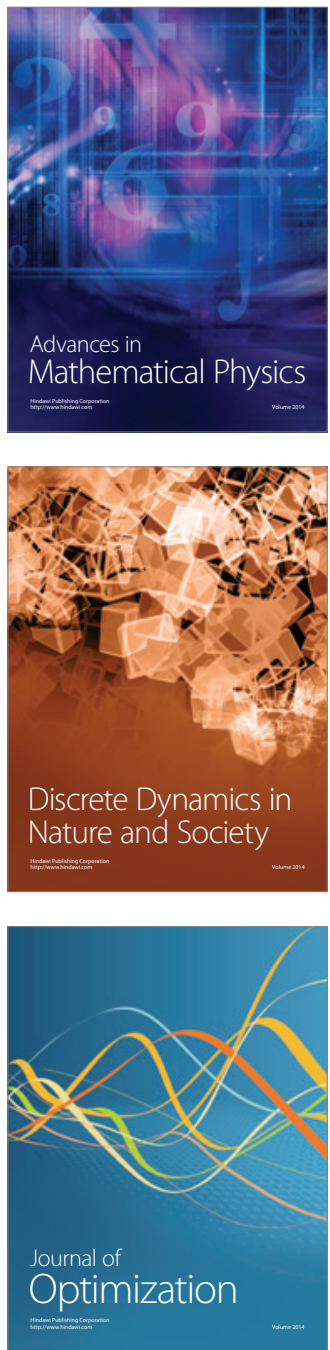